\title{
La Enseñanza de la Morfología a través del Enfoque Comunicativo y el Aprendizaje Cooperativo en Educación Secundaria: Propuesta Práctica ${ }^{1}$
}

\author{
Ana María AguILAR LóPEZ \\ Universidad de Burgos \\ Dpto. de Didácticas Específicas. Área de Didáctica de la Lengua y la Literatura. \\ amaguilar@ubu.es
}

Recibido: 2 de febrero de 2015

Aceptado: 16 de marzo de 2015

\section{RESUMEN}

Presentamos a continuación una propuesta práctica que consta de dos sesiones implementadas con diferentes cursos de Educación Secundaria Obligatoria (ESO) del Colegio Círculo Católico, sito en la ciudad de Burgos. Cada sesión tiene una duración de 55 minutos. Dichas sesiones pretenden trabajar la morfología de la lengua española. Su diseño se ha realizado teniendo en cuenta las bases teóricas del enfoque comunicativo y del aprendizaje cooperativo.

Palabras clave: morfología, ESO, enfoque comunicativo, aprendizaje cooperativo.

Teaching morphology trough communicative approach and cooperative learning in Secondary Education: practical proposal

\begin{abstract}
We will be presenting the following practical proposal that will consist of two sessions implemented with different courses of Secondary Education (ESO) of the Colegio Círculo Católico (Catholic School Group), located in the city of Burgos. Each session lasts 55 minutes. These sessions focus on the morphology of the Spanish language. Its design has
\end{abstract}

${ }^{1}$ Quisiéramos agradecer al personal del Colegio Círculo Católico de Burgos que nos haya facilitado el acceso al alumnado para poner en marcha estas actividades, en especial al Dr. D. Pablo de Andrés Zabaleta, director pedagógico del centro, $\mathrm{D}^{\mathrm{a}}$ Leyre Andrés Pérez, coordinadora del primer ciclo de ESO y $\mathrm{D}^{\mathrm{a}}$. Gemma Perales Barrenengoa, profesora de Lengua castellana y literatura en ESO. Así mismo agradecemos la amable ayuda recibida por parte de la Dra. D ${ }^{a}$ Gloria Diez en la traducción del resumen al francés y por parte del traductor D. Ismael Saiz Herrera en la traducción al inglés. 
been carried out by keeping in mind the theoretical basis of the communicative approach and cooperative learning.

Key words: morphology, ESO, communicative approach, cooperative learning

L'enseignement de la morphologie à travers de l'approche communicative et l'apprentissage coopératif en Éducation Secondaire: proposition pratique

\section{RÉSUMÉ}

Nous présentons ensuite une proposition pratique qui se compose de deux séances mises en application avec de différents cours d'Éducation Secondaire Obligatoire (ESO) du Colegio Círculo Católico (Collège du Cercle Catholique), situé à la ville de Burgos. Chaque séance a une durée de 55 minutes. Les dites séances essaient de travailler la morphologie de la langue espagnole. Son dessin (conception) a été réalisé en tenant compte des bases théoriques du point de vue de l'approche communicative et de l'apprentissage coopératif.

Mots-clé: morphologie, ESO, approche communicative, apprentissage coopératif

SUMARIO: 1. Marco teórico; 2. Propuesta práctica; 2.1. Primera sesión; 2.2. Segunda sesión; 3. Conclusiones; 4. Bibliografía.

\section{MARCO TEÓRICO}

Según lo referido en el Real Decreto 1631 por el que se establecen las enseñanzas mínimas correspondientes a la Educación Secundaria Obligatoria (ESO en adelante) (2006, 730), el desarrollo de la competencia comunicativa es la razón de ser de la asignatura de Lengua Castellana y Literatura en esta etapa, ahora bien, ¿qué lugar ocupa la morfología en esa competencia comunicativa? Para responder a este interrogante nos remitimos al Marco Común Europeo de Referencia para las Lenguas (Consejo de Europa, 2002), documento en el que se incluyen dentro de la competencia comunicativa las competencias lingüísticas, la competencia sociolingüística y las competencias pragmáticas. Las competencias lingüísticas son, según este documento, seis, a saber: la léxica, la gramatical, la semántica, la fonológica, la ortográfica y la ortoépica (ibíd., 107). Los contenidos morfológicos se incluyen en la competencia gramatical junto con los sintácticos.

El desarrollo de la competencia comunicativa es también el objetivo último que persigue el enfoque comunicativo, de ahí que hayamos tenido en cuenta esta metodología a la hora de diseñar nuestra propuesta práctica² ${ }^{2}$.

En principio todo método de enseñanza se adhiere a unas ideas teóricas que finalmente justifican que se proceda en el aula de una manera u otra (práctica). Estas ideas teóricas atañen en nuestro caso a la lingüística y al aprendizaje (Santos

${ }^{2}$ El enfoque comunicativo se originó en el ámbito de las lenguas extranjeras, pero su aplicación a la lengua materna ha sido defendida por autores como María José del Río (1993). 
Gargallo, 1999, 48-49). Por lo que respecta a las primeras, a las teorías lingüísticas, cabe destacar que tanto el enfoque comunicativo, como el enfoque por tareas, que surge a partir de él, conciben la lengua como un instrumento a servicio de la transmisión de significados y, en última instancia, de la comunicación entre las personas. Nuestra propuesta parte también de este punto.

Como explica Miquel Llobera (VV. AA., 2000, 5) la enseñanza comunicativa de una lengua no tiene por qué ser una oposición a la enseñanza gramatical y literaria, pues en ella se da cabida también a estos elementos. Llobera (ibíd., 7) avisa de los riesgos que entraña tomar una postura extremista al considerar que el enfoque comunicativo no es compatible con la enseñanza-aprendizaje de las competencias lingüísticas. Él es partidario de adoptar una postura ecléctica y manifiesta que no se puede dar por hecho ni que un buen dominio de la fonología, morfología, sintaxis y un buen conocimiento del léxico tan vasto como sea posible aseguran un buen uso de la lengua, ni que el aprendizaje de las formas lingüísticas, emparentadas directamente con la gramática, es inútil porque lo importante es comunicar. En definitiva, se trata de que dicho aprendizaje no implique una desconexión entre el uso y la forma, sino, antes bien, que se contemplen ambas vertientes en el aula. Así Isabel Santos Gargallo $(1999,81)$ al hablar del enfoque por tareas manifiesta que en éste "la descripción del sistema ha de llevarse a efecto según criterios de análisis pragmático y discursivo, es decir, atendiendo al funcionamiento del sistema en uso". Esta idea queda también reflejada en el Real Decreto 1631 (2006, 731), en el que se asume que el bloque destinado al Conocimiento de la lengua, dentro del cual entrarían los contenidos morfológicos, ha de interrelacionarse con el resto de bloques. Por su parte, Mantecón y Zaragoza $(1998,5)$ aconsejan que se relacione la competencia gramatical con la competencia discursiva, pues consideran que aquélla ha de estar orientada en última instancia al desarrollo de ésta.

La relación entre elementos de diferentes competencias es posible gracias a que todos los elementos de la competencia comunicativa se interrelacionan entre sí y se plasman a través de la actuación o, lo que es lo mismo, a través de la interacción, comprensión y expresión orales y escritas.

Por lo que respecta a las teorías de aprendizaje, hemos de señalar que la propuesta de una enseñanza comunicativa de la lengua se ha nutrido desde sus orígenes, entre otras teorías de aprendizaje, del constructivismo (Pastor, 2004, 156) que considera al discente como núcleo de todo el proceso de aprendizaje. Esto en su día supuso todo un cambio y contribuyó a paliar el descontento generado por una tradición de métodos de enseñanza anteriores centrados en cómo el maestro podía enseñar ciertos contenidos o en los contenidos en sí, más que en cómo los aprendía el alumno.

El constructivismo, que como explican Ertmer y Newbay (1993) no es sino una rama del cognitivismo, recurre entre otras estrategias a la presentación de 
perspectivas múltiples o, lo que es lo mismo, al aprendizaje cooperativo ${ }^{3}$, pues éste permite mostrar a los alumnos cómo se construye el conocimiento, invita a compartir puntos de vista diversos, incluso opuestos, y a promover la colaboración entre los miembros de un grupo para que éste vea la variedad de perspectivas que pueden surgir al hilo de un problema concreto.

Para Mantecón y Zaragoza $(1998,15)$ a la hora de plantearnos llevar al aula actividades basadas en la idea de aprendizaje cooperativo, debemos explicar muy bien el objetivo de la actividad. Además hemos de tener en cuenta que dicha actividad ha de favorecer la creación de un buen clima en clase, en el que los conflictos cognitivos que puedan surgir a nivel personal o grupal, se resuelvan mediante la interacción con otros miembros del grupo, de modo que:

...los alumnos que ya saben una cosa aprenden más porque explican lo que saben y lo tienen que verbalizar. Esto les ayuda a formular lo que han aprendido. En cambio, para aquéllos que no lo saben, se lo explica uno de su edad y con su mismo lenguaje. Todo resulta más comprensible. Además, y esto es lo esencial, todos están en clase con una actitud mucho más participativa, responsable. Son protagonistas de lo que aprenden (...) los alumnos se desarrollan ellos mismos como un grupo heterogéneo a través de la deliberación colectiva sobre sus prácticas lingüísticas.

Por estas razones, el aprendizaje cooperativo se ha elegido como otro de los pilares que se tienen en consideración a la hora de diseñar las actividades del siguiente apartado.

\section{PROPUESTA PRÁCTICA}

La propuesta práctica que presentamos aquí consta de dos sesiones que se diseñan e implementan con alumnado de segundo curso de la ESO y que tienen una duración de 55 minutos cada una.

\subsection{Primera sesión}

Esta primera sesión se ha desarrollado con el grupo de $2^{\circ} \mathrm{A}$, integrado por 30 alumnos con los que hemos realizado dos actividades. La primera de ellas es la titulada Pero ¿Cuántas somos?

- Objetivos: los objetivos con los que nos planteamos esta actividad son: repasar las categorías gramaticales de manera descontextualizada, para después poder utilizarlas en la siguiente actividad. Involucrarse en el grupo

\footnotetext{
${ }^{3}$ Según Olsen y Kagan (op. cit. Oxford, 1997, 443) el aprendizaje cooperativo es definido como "group learning activity organized so that learning is dependent on the socially structured exchange of information between learners in groups and in which each learner is held accountable for his or her own learning and is motivated to increase the learning of others".
} 
para conseguir una mayor localización de palabras y para empezar a crear lazos grupales.

- Organización social: por cuestiones de tiempo, nosotros hacemos esta actividad con la misma organización social que la actividad siguiente. Como en total tenemos treinta alumnos en $2^{\circ} \mathrm{A}$, hacemos seis grupos de cinco alumnos ${ }^{4}$. Pero en otras circunstancias esta misma actividad podría hacerse por parejas o grupos de tres o cuatro alumnos.

- Recursos: llevamos al aula cuatro papeles o cartulinas de color en cada uno de ellos aparece un número del 1 al 4 , también va a precisar de cinta adhesiva y fotocopias de una hoja en la que aparezcan las Tabla 1 y 2.

\section{¿Cuántas palabras puedes encontrar? ${ }^{5}$}

1. ROCASTORBELLINOMEABURROAPARATOS

2. AISLAMIENTOFRACASARABRASAR

3. PROPIEDADATERRIZARCONSUELO

4. ACANTILADOSAMOROSO

Tabla 1. Actividad Pero ¿cuántas somos? Material para los alumnos.

\begin{tabular}{c|c|c|c|c|c|c|}
\cline { 2 - 7 } & VERBOS & $\begin{array}{c}\text { PRONOM- } \\
\text { BRES }\end{array}$ & $\begin{array}{c}\text { ADJE- } \\
\text { TIVOS }\end{array}$ & $\begin{array}{c}\text { CONJUN- } \\
\text { CIONES }\end{array}$ & $\begin{array}{c}\text { PREPO- } \\
\text { SICIONES }\end{array}$ & $\begin{array}{c}\text { SUSTANTI- } \\
\text { VOS }\end{array}$ \\
\hline 1 & & & & & & \\
\hline 2 & & & & & & \\
\hline 3 & & & & & & \\
\hline 4 & & & & & & \\
\hline
\end{tabular}

Tabla 2. Actividad Pero ¿cuántas somos? Material para los alumnos.

${ }^{4}$ Debido a que no conocemos previamente al alumnado con el que vamos a realizar la propuesta práctica y a que el tiempo con el que contamos es simplemente de 55 minutos para cada una de las dos sesiones, los grupos se organizan atendiendo al criterio de cercanía o proximidad física de unos alumnos con otros y no al nivel alcanzado en la asignatura, a las relaciones sociales generadas entre los alumnos, etc.

5 Solución: ROCASTORBELLINOMEABURROAPARATOS (roca, oca, ocas, as, rocas, casto, castor, torbellino, orbe, lino, no, me, mea, a, burro, aburro, par, para, ara, tos, os, aparatos, o, u, e). AISLAMIENTOFRACASARABRASAR (a, isla, la, miento, en, mi, aislamiento, frac, casar, casará, asa, as, ar, acá, casa, fracasar, fracasará, brasa, abrasar, asar, asará, ras, rasa, rasar, abra, abras). PROPIEDADATERRIZARCONSUELO (pro, pie, edad, propiedad, piedad, edad, da, dad, dada, date, ate, te, a, aterrizar, riza, rizar, iza, izar, zar, zarco, arco, con, consuelo, suelo, lo). ACANTILADOSAMOROSO (a, can, tila, ti, la, do, dos, lado, lados, os, osa, amor, oso, amoroso, moro, moroso, oro, adosa, osa, so, o). 


\section{- Procedimiento:}

Antes de entrar en el aula, colocamos en las paredes el material que vamos a emplear para esta sesión; en nuestro caso aprovechamos el recreo para hacerlo, de forma que, a la vuelta de éste, los alumnos se encuentran ya con el aula decorada. En concreto, para esta actividad, colgamos en la pared lateral las cartulinas con los números del 1 al 4.

Repartimos a cada grupo de cinco alumnos dos de estas hojas con las Tablas 1 y 2, de manera que haya una por pareja y trío. Explica a los estudiantes que, de manera conjunta, cada grupo ha de encontrar la mayor cantidad posible de palabras en cada uno de los cuatro ejemplos de la Tabla 1, teniendo en cuenta que una misma letra puede servir para varias palabras y que también se admiten formas conjugadas de los verbos, singulares, plurales, etc.

A medida que las van encontrando, los miembros del equipo deben decirlas en alto, anotarlas y ubicarlas en la fila correspondiente de la Tabla 2. Para ello deben ponerse de acuerdo. Se les avisa de que disponen de cinco minutos para este paso.

Al objeto de que la corrección no se prolongue demasiado, pedimos a los equipos que cuenten el total de palabras que han encontrado en cada uno de los cuatro ejemplos. El equipo que más tenga en cada uno de ellos colgará en la pared, debajo del papel o cartulina con el número correspondiente, uno de los dos folios donde ha anotado sus respuestas. Esto es, si un equipo ha tenido el mayor número de palabras en el primer ejemplo, lo cuelga debajo del 1, si un mismo equipo ha tenido el mayor número de palabras en los ejemplos 2 y 3 , se ponen los números 2 y 3 juntos y debajo el folio de ese grupo. Cuando están colgados todos, el resto de grupos se pasa por la pared en la que están los ejemplos con mayor cantidad de palabras y completan su Tabla 2 con las palabras que les falte.

- Evaluación metodológica:

Esta actividad nos sirve de repaso y para detectar posibles problemas respecto a la clasificación morfológica. En realidad es un poco la antesala para la siguiente actividad.

En el momento en el que la realizamos no dimos indicaciones específicas sobre cómo gestionar el trabajo, aunque quizá podríamos ayudar a los alumnos si les decimos que primero busquen las palabras más largas y después traten de identificar qué otras palabras cortas hay dentro de las primeras.

Además, debido a que solo teníamos una sesión de 55 minutos, la corrección fue un poco diferente, los alumnos que más palabras habían encontrado por casa ejemplo, colgaron en la pared su folio debajo del número correspondiente y pedimos a los alumnos que, al finalizar la sesión, es decir, en el cambio de hora o, en su defecto, al final de la jornada, comprobaran las respuestas de los grupos con mayor número de palabras.

La segunda actividad que realizamos con este grupo es la titulada De compras. 
- Objetivos: los objetivos con los que se concibe esta actividad son: Repasar las categorías gramaticales. Entrenarse en la comprensión de explicaciones gramaticales. Valorar las opciones lúdicas a las que se presta la morfología. Colaborar con el grupo para conseguir un fin.

- Organización social: mantenemos la agrupación de la actividad anterior, es decir, seis pequeños grupos de cinco alumnos cada uno.

- Recursos: llevamos al aula veinte anuncios con eslóganes recortados de la prensa escrita, también podrían ser seleccionados de entre la propaganda diaria. Introducimos cada anuncio en una funda plastificada para que no se rompan durante la actividad y sea más sencilla su manipulación. Estos anuncios así dispuestos se han pegado antes de iniciar la sesión en la parte frontal del aula, donde está la pizarra, por lo que además necesitamos la cinta adhesiva empleada en la actividad anterior.

Con la información ofrecida en los anuncios seleccionados, configuramos previamente la Tabla 4 formada por dos columnas. En la columna de la izquierda escribimos el producto o empresa anunciadora y en la de la derecha copiamos los respectivos eslóganes. La Tabla 4 la fotocopiamos doce veces y dejamos dos copias en cada grupo de cinco alumnos, para que todos tengan ocasión de seguir la actividad. Las Tablas 3 y 5 las fotocopiamos tantas veces como pequeños grupos tengamos en el aula. En nuestro caso seis veces.

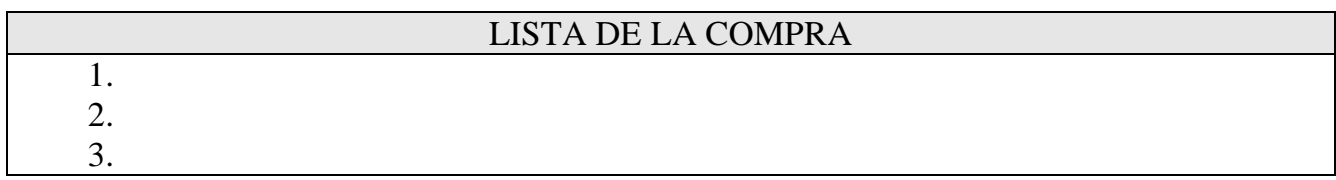

Tabla 3. Actividad De compras. Primera parte: material para que los alumnos escriban los eslóganes en la lista de la compra.

\begin{tabular}{|c|c|}
\hline EMPRESAS/PRODUCTOS & ESLÓGANES \\
\hline Michelin & Disfruta al volante con máxima precisión \\
\hline Biotherm Homme & Sacia la sed de tu piel \\
\hline Fiat 500 & Para los que sueñan con una ciudad mejor \\
\hline Haier (frigorífico) & La conquista del espacio \\
\hline People & Las buenas ideas no se detienen nunca \\
\hline Estola (vino) & Me gusta tu estilo \\
\hline Casio (reloj) & Su dureza habla de ti \\
\hline Iberia & Un restaurante con tantas estrellas tenía que estar en el cielo \\
\hline Citroën DS4 & Di no a lo establecido \\
\hline Helios (mermelada) & La primera mermelada elaborada por abejas \\
\hline Nescafé (Dolce gusto) & El café puede ser un descubrimiento \\
\hline AEG Frigoríficos & Perfecta conservación consumiendo menos que una bombilla \\
\hline Solac Cafetera & Disfruta como nunca con la marca de café que elijas \\
\hline
\end{tabular}




\begin{tabular}{|c|c|}
\hline LG & Esto sí son smartphones \\
\hline Longines (reloj) & Elegance ist an attitude \\
\hline Telefónica & ¿Quieres jugar en mi equipo? \\
\hline Mercedes Benz & Por si sientas la cabeza o todo lo contrario \\
\hline Vodafone & En Vodafone formamos parte de tu ilusión \\
\hline BBVA & La sorpresa no entra en tus planes \\
\hline Peugeot 508 & Más espacio para ti. Más espacio para todo lo demás \\
\hline
\end{tabular}

Tabla 4. Actividad De compras. Primera parte: Listado de eslóganes para los alumnos.

\begin{tabular}{|c|c|c|c|}
\hline \multicolumn{5}{|c|}{ LOQUE QUEREMOS COMPRAR } \\
\hline ESLOGAN & $\begin{array}{c}\text { DESCRIPCIÓN } \\
\text { MOROLÓGICA DEL } \\
\text { ESLOGAN }\end{array}$ & $\begin{array}{c}\text { PRODUCTO/ } \\
\text { EMPRESA }\end{array}$ & $\begin{array}{c}\text { ¿COINCIDE CON LA } \\
\text { DESIPCIÓN MORFOLÓGICA } \\
\text { DEO ESLOGAN DE LA } \\
\text { LISTA? ¿CUÁL? }\end{array}$ \\
\hline & & & \\
\hline & & & \\
\hline & & & \\
\hline & & & \\
\hline
\end{tabular}

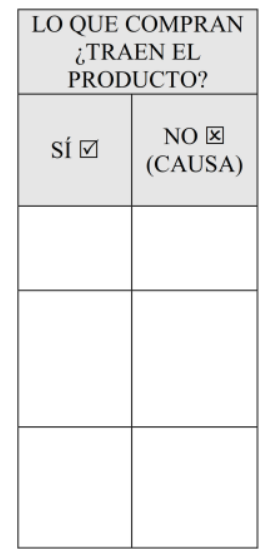

Tabla 5. Actividad De compras. Segunda parte: material para comprobar si los productos de los compradores son los que se pedían.

- Procedimiento:

Antes de comenzar la clase, entramos en el aula y pegamos con cinta adhesiva todos los anuncios en la pared en la que se encuentra la pizarra. Si, por las dimensiones del aula, no cupieran todos, los pegaríamos en las paredes laterales, procurando invadir sólo el espacio de éstas que estuviera más cercano a la pared de la pizarra.

Comentamos a los alumnos que hace un día estupendo para ir de compras, pero, como nuestra obligación es estar en clase, en vez de ir a las tiendas, las tiendas han llegado al aula a través de anuncios publicitarios. De ahí que los únicos productos que se puedan comprar sean los que figuran en los anuncios de la pared frontal (en la que está la pizarra).

Informamos a los alumnos de que cada grupo ha de designar a dos miembros para que vayan a hacer la compra. Una vez designados, todos los alumnos compradores de cada grupo se acercan a la pared frontal y suben a la tarima. Pero éstos aún no saben qué productos quiere comprar su grupo.

Por ello, al resto de los miembros de cada grupo, esto es, a quienes están sentados en las mesas, les informamos de que vamos a entregarles varios folios: en 
uno de ellos (Tabla 3) aparece una lista de la compra vacía, mientras que en el otro (Tabla 4) figuran, no necesariamente en ese orden, los productos y empresas de los anuncios que aparecen en la pared frontal del aula así como sus correspondientes eslóganes. De esta manera, los alumnos podrán saber cuáles son los productos que están a la venta sin necesidad de levantarse.

Los miembros de cada grupo que permanecen sentados, tienen por cometido seleccionar tres productos de la Tabla 4 y hacer con ellos la lista de la compra (Tabla 3). Sin embargo, y dado que estamos en clase de lengua, la lista de la compra no se va a hacer a la manera tradicional, les proponemos que, en vez de escribir el producto, los alumnos describan la composición morfológica del eslogan que anuncia el producto, es decir, las categorías gramaticales que lo conforman así como referencias a morfemas que pudieran dar pistas sobre el producto que se pretende conseguir, tal y como figura en el ejemplo ofrecido en la Tabla 6. Además se les avisa de que no pueden escribir ninguna palabra que oriente sobre el significado, es decir, deberán evitar explicaciones del tipo a "presente de indicativo, tercera persona del singular del verbo estar".

\begin{tabular}{|c|c|}
\hline PRODUCTO/EMPRESA & \multicolumn{1}{c|}{ ESLOGAN } \\
\hline Pan's and Company & Pan's está que cruje \\
\hline \multicolumn{2}{|c|}{ LISTA DE LA COMPRA } \\
\hline \multicolumn{2}{|c|}{$\begin{array}{l}\text { 1. Sustantivo + verbo en presente de indicativo, tercera persona del singular + conjunción + } \\
\text { verbo en presente de indicativo de la tercera persona del singular. }\end{array}$} \\
\hline
\end{tabular}

Tabla 6. Actividad De compras. Ejemplo de descripción morfológica de los eslóganes

Una vez que todos los grupos han completado sus respectivas listas de la compra, se las entregan a los dos compañeros compradores de su grupo para que les traigan los productos elegidos. A medida que éstos localicen los productos, irán cogiendo los anuncios pegados en la pared. Cuando los tengan todos, los llevarán a su grupo.

Los alumnos han de tener en cuenta que sólo hay un producto de cada eslogan y por ello, al igual que sucede en la vida real, si hay mucha demanda es probable que se agote el recurso deseado. Si dos grupos han descrito en sus respectivas listas de la compra el eslogan de un mismo producto, sólo uno podrá conseguirlo, de ahí la necesidad de ser rápidos en la localización de los artículos. Llegados a este punto, hacemos hincapié en el hecho de que los alumnos compradores de cada grupo han de trabajar de forma conjunta, lo que implica que no se pueden repartir el trabajo, sino que han de desplazarse juntos durante la búsqueda de los productos deseados.

Explicada la actividad, nos aseguramos de que todos han comprendido tanto el objetivo de ésta, como el papel que cada uno ha de desempeñar. Preguntamos por posibles dudas y después repartimos las Tablas 3 y 4 entre los grupos que están sentados. Mientras éstos deciden los productos y describen morfológicamente los eslóganes, los alumnos compradores observan la publicidad con el fin de localizar 
los eslóganes y familiarizarse con ellos. Animamos a los que desempeñan el rol de compradores a que también intenten mentalmente describirlos para sí mismos desde un punto de vista morfológico, ya que ello puede ayudarles a identificar los productos que quiere su grupo más rápido.

Después, cada grupo entrega a sus compradores la Tabla 3 completada y mientras éstos compran, repartimos la Tabla 5 a los miembros de los grupos que están sentados, indicándoles que han de rellenar las columnas que figuran bajo el epígrafe Lo que queremos comprar (Eslogan, Descripción morfológica del eslogan, Producto/empresa y ¿Coincide con la descripción morfológica de otro eslogan de la lista?). Tras dejarles un tiempo prudencial de búsqueda de los productos, los alumnos compradores han de volver a sus respectivos grupos. Será entonces el momento de que los grupos, ya completos, rellenen las columnas que aparecen bajo el epígrafe Lo que compran de la Tabla 5. En una de ellas se pide que expliquen el motivo por el que no han traído el producto que quería el grupo, las causas pueden ser varias: bien que no estuviera disponible el anuncio, bien que haya habido una confusión por parte de los compradores o de los demandantes o bien que varios productos coincidan en la formación morfológica del eslogan.

Finalmente hacemos una puesta en común en gran grupo para comprobar cuántos grupos han conseguido los productos que querían comprar y realizamos la corrección de la actividad.

- Evaluación metodológica:

Pese a que tuvimos que controlar muy bien la información que dábamos en cada momento y a que esta información era bastante, los alumnos comprendieron a la perfección la mecánica de la actividad y la realizaron sin ningún tipo de incidente digno de ser mencionado.

Nos llamó la atención, eso sí, la actitud de dos compradores que intentaron buscar el camino rápido y, en vez de hacer la actividad tal cual se les pedía, preguntaron por los productos desde la tarima (parte delantera del aula) al resto de su grupo que estaba sentado en las sillas, para así coger los anuncios sin necesidad de tener que leer ni descifrar la descripción morfológica del eslogan. Si bien, el hecho de que el resto del grupo no pudiera identificar desde el lugar en el que estaba sentado la imagen ni los eslóganes de los anuncios, pues estaba a una cierta distancia de la zona delantera en la que estaban colgados los anuncios, unido al hecho de que de que llamáramos la atención repetidas veces a estos dos compradores y al hecho de que varios anuncios se referían al mismo producto pero de diferentes marcas, provocó que no fuera tan sencillo hacer trampas, es más, este grupo en cuestión no fue uno de los dos que consiguieron todos los productos.

Pese a todo, sí nos planteamos para futuras realizaciones de la misma actividad, la necesidad de remarcar que la única comunicación entre los compradores y demandantes ha de ser a través de la lista de la compra y que si se infringe esta cláusula, el grupo será penalizado de algún modo. 
Por otro lado con relación al reparto interno de tareas en cada grupo, en nuestro caso no dimos más indicaciones de las que se han especificado, en parte porque, como ya se ha dicho, no conocíamos previamente al grupo de alumnos. Pese a todo, consideramos que podría ayudar a los alumnos el hecho de que el profesorado asignara los roles de compradores y también que marcara dentro de cada grupo que permanece sentado quién escribe la lista y cómo se ha de gestionar ese trabajo. En este sentido podría considerarse la posibilidad de que, si se dispusiera del tiempo suficiente para ello, cada alumno eligiera un eslogan y que el resto de alumnos del grupo decidiera si es correcta la descripción morfológica que hace o no, aunque también hay que tener en cuenta la cantidad de alumnos por grupo para que no se alargue demasiado este paso, pues los compradores están esperando la lista de su grupo.

Consideramos que muy probablemente esta misma actividad también podría haber sido realizada por alumnos de $1^{\circ}$. Además, en función de los contenidos que se estén viendo en el aula, al profesorado le puede interesar que los alumnos sean más o menos exhaustivos en la descripción morfológica de los eslóganes, es decir, puede ser que el profesorado quiera que los alumnos no sólo señalen las categorías gramaticales de las palabras, sino que también descompongan cada palabra y señalen los morfemas dependientes, afijos y lexemas o que indiquen si son palabras primitivas, derivadas, compuestas, etc.

\subsection{Segunda sesión}

Esta sesión se ha desarrollado con el grupo de $2^{\circ}$ B que tiene 29 alumnos en lista. Durante esta sesión llevamos a la práctica la actividad titulada El texto morfológico que consta de varias partes.

- Objetivos: los objetivos perseguidos son practicar las diferentes categorías gramaticales. Reflexionar sobre la ambigüedad que en este sentido tienen algunas de las palabras. Apreciar las relaciones entre los diferentes elementos del sistema. Aplicar conocimientos relacionados con la composición y las características de los textos narrativos.

- Organización social: para esta actividad organizamos el aula en pequeños grupos. Como tenemos veintinueve alumnos, hacemos ocho grupos en total: cinco de ellos formados por cuatro alumnos y tres tríos.

- Organización espacial: durante esta actividad es preciso que los alumnos interactúen, por lo que necesitamos que cada grupo se siente en torno a una o varias mesas, de manera que puedan verse bien.

- Recursos: para esta actividad empleamos dos textos de Raymond Queneau extraídos del libro Ejercicios de estilo (1987), éstos son: "Relato" (ibíd., 64) y "Partes de la oración" (ibíd., 135), que a su vez se corresponden con dos versiones de una misma anécdota. 
Hacemos una fotocopia de la Tabla 7 en la que se incluye la versión titulada "Relato":

Una mañana a mediodía, junto al parque Monceau, en la plataforma trasera de un autobús casi completo de la línea $S$ (en la actualidad el 84), observé a un personaje con el cuello bastante largo que llevaba un sombrero de fieltro rodeado de un cordón de fieltro en lugar de cinta. Este individuo interpeló, de golpe y porrazo, a su vecino, pretendiendo que le pisoteaba adrede cada vez que subían o bajaban viajeros. Pero abandonó rápidamente la discusión para lanzarse sobre un sitio que había quedado libre.

Dos horas más tarde, volví a verlo delante de la estación de Saint Lazare, conversando con un amigo que le aconsejaba disminuir el escote del abrigo haciéndose subir el botón superior por algún sastre competente.

Tabla 7. Actividad El texto morfo-lógico. Texto de R. Queneau, versión: "Relato".

En la segunda versión, "Partes de la oración", el autor no hace sino clasificar, según la categoría gramatical, las palabras que contendría una anécdota cuyo contenido es el que se cuenta en la versión "Relato". Hacemos dos fotocopias de la Tabla 8 para cada grupo de trabajo, lo que, en nuestro caso, supone un total de dieciséis copias ${ }^{7}$.

ARTÍCULOS: el, la, los, un, una al.

SUSTANTIVOS: mañana, mediodía, plataforma, autobús, línea, S, Parque, Monceau, joven, cuello, sombrero, galón, lugar, cinta, vecino, pie, viajero, discusión, sitio, hora, estación, san(to), Lázaro, conversación, compañero, escote, abrigo, sastre, botón.

ADJETIVOS: trasera, completo, rodeado, gran(de), libre, largo, trenzado.

VERBOS: ver, llevar, interpelar, pretender, pisotear, subir, bajar, abandonar, precipitar(se), volver, ver, decir, disminuir, hacer, subir.

PRONOMBRES: yo, él, se, - le lo, el cual, que, éste.

ADVERBIOS: poco, cerca, muy, adrede, rápidamente, más, tarde.

PREPOSICIONES: a, hacia, en, de, sobre, ante, con, por, en.

CONJUNCIONES: que, o, pero.

Tabla 8. Actividad El texto morfo-lógico. Texto de R. Queneau, versión: "Partes de la oración".

${ }^{6}$ Gérad Genette (Queneau, 1987, 17) considera que éste sería el texto base del que parten las demás versiones, pese a que Queneau no lo presenta como tal ni es la primera versión que escribe.

${ }^{7}$ Decidimos hacer dos copias por grupo, incluso en los tríos, porque, al colocarse los alumnos alrededor de las mesas, algunos de ellos están en frente de otros compañeros. Si en esta situación han de leer y sólo hay un texto, unos tendrán el texto en posición normal y otros deberán leerlo al revés, lo cual puede inclinarlos a que se centren por encima de todo en la descodificación y no en el significado de lo descodificado. 
Además, con las palabras que componen el texto "Partes de la oración", confeccionamos la Tabla 9. Después recortamos cada celda y hacemos tarjetas con cada una de ellas, de este modo un juego completo incluye treinta y ocho cartulinas o tarjetas. Preparamos tantos juegos de tarjetas como cantidad de grupos vayamos a tener en clase, en nuestro caso ocho juegos para 29 alumnos.

\begin{tabular}{|c|c|c|c|}
\hline $\begin{array}{l}\text { Bajar } \\
\text { ABANDONAR } \\
\text { PRECIPITARSE }\end{array}$ & $\begin{array}{l}\text { Ver } \\
\quad \text { Llevar } \\
\text { Interpelar }\end{array}$ & $\begin{array}{l}\text { Pretender } \\
\text { Pisotear } \\
\quad \text { Subir }\end{array}$ & $\begin{array}{l}\text { of } \\
\text { De } \\
\text { \&n }\end{array}$ \\
\hline $\begin{array}{ll}\text { MUY } & \\
& \text { TARDE }\end{array}$ & MANANA & Parque Monceau & $\begin{array}{ll}\text { LE } & \text { LE } \\
\end{array}$ \\
\hline $\begin{array}{ll}\text { Largo } & \\
& \text { Trenzado }\end{array}$ & $\begin{array}{l}\text { Poco } \\
\text { CERCa }\end{array}$ & ÉL & Una \\
\hline $\begin{array}{c}\text { Santo } \\
\text { Lázaro } \\
\text { conversación } \\
\text { compañero }\end{array}$ & $\begin{array}{l}\begin{array}{c}\text { Vecino } \\
\text { Discusión } \\
\text { Viajero }\end{array} \\
\text { Pie }\end{array}$ & $\begin{array}{l}\text { Sobre } \\
\text { Por } \\
\qquad \text { Ante }^{\text {En }}\end{array}$ & $\begin{array}{l}\text { Escote } \\
\text { Sastre } \\
\text { Abrigo } \\
\text { Botón }\end{array}$ \\
\hline HACIA & Rápidamente & Más & $\begin{array}{c}\text { PLATAFORMA } \\
\text { AUTOBÚS }\end{array}$ \\
\hline Pero & YO & Mediodía & ÉSTE \\
\hline $\begin{array}{ll}\text { El cual } \\
\text { Que }\end{array}$ & QUE $\quad 0$ & ADREDE & LÍNEA "S" \\
\hline $\begin{array}{l}\text { JOVEN } \\
\text { SOMBRERO } \\
\text { CUELLO }\end{array}$ & $\begin{array}{l}57790 \\
\text { Extacón } \\
\text { Hora }\end{array}$ & $\begin{array}{l}\text { Ealón } \\
\text { Lugar } \\
\text { Einta }\end{array}$ & $\begin{array}{l}\text { Traserg } \\
\text { Rodeado } \\
\text { Completo }\end{array}$ \\
\hline $\begin{array}{l}\text { Grande } \\
\text { Libre }\end{array}$ & $\begin{array}{cc} & \text { Volver } \\
\text { Ver } & \text { Decir }\end{array}$ & $\begin{array}{l}\text { Disminuir } \\
\text { Hacer }\end{array}$ & Un \\
\hline L'os & Al & & \\
\hline
\end{tabular}

Tabla 9. Actividad El texto morfo-lógico. Uno de los ocho juegos cuyas celdas se recortan para hacer tarjetas.

- Procedimiento:

Una vez en el aula, pegamos en la pizarra de la clase carteles con las diferentes categorías gramaticales que aparecen en el texto de la versión Partes de la oración, (véase Figura 1). 


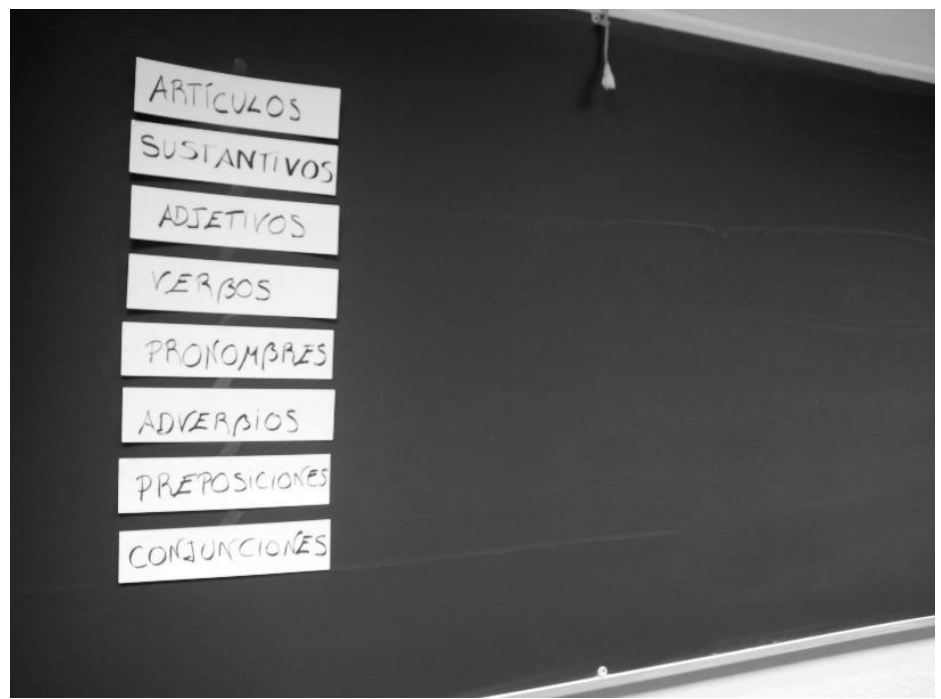

Fig. 1

Como se puede apreciar, los carteles están situados en el mismo orden que aparece en el texto de Queneau. Mientras pegamos los carteles con cinta adhesiva, introducimos la actividad preguntando a los alumnos por cada uno de esos conceptos, ello nos permite calibrar sus los conocimientos previos y asegurarnos de que todos los alumnos van a tener opción de partir de unos conocimientos comunes.

Seguidamente estructuramos los ocho grupos, una vez más al no conocer a los alumnos y al disponer de sólo 55 minutos, hacemos los grupos según la cercanía física de unos alumnos con otros. A cada uno le entregamos un juego de tarjetas (celdas recortadas de la Tabla 9) sujeto con clips que los alumnos no podrán quitar hasta que se les dé la indicación oportuna para hacerlo. Con ello se pretende evitar que comiencen antes los grupos que primero reciban cada juego de tarjetas, ya que esto ocasionaría que tuvieran cierta ventaja respecto al grupo que recibe en último lugar el juego de tarjetas.

A continuación decimos a los alumnos que quiten los clips y que clasifiquen en sus mesas las cartulinas según las categorías gramaticales que aparecen en los carteles de la pizarra. Como se puede apreciar en la Tabla 9, algunas celdas incluyen varias palabras de la misma categoría gramatical, la agrupación de palabras es necesaria para no hacer tan extensa la actividad y también para eliminar las posibles ambigüedades que puedan surgir al no haber un contexto, es decir, una palabra como sobre podría resultar ambigua a la hora de clasificarla gramaticalmente, puesto que puede ser un sustantivo o una preposición. Sin embargo, al escribir esta palabra en una cartulina junto con otras preposiciones, se disipa la duda en cuanto a cuál de las dos opciones es la que tenemos. Por esto informamos a los alumnos de que algunas palabras pueden pertenecer a diferentes 
categorías gramaticales, pero que, si hay alguna palabra que pueda resultar ambigua en este sentido, han de guiarse por la categoría gramatical que tenga el resto de palabras que la acompañan en la tarjeta.

Una vez que los grupos acaban de clasificar las tarjetas, preguntamos por algunas de las palabras que han podido causar más problemas como: joven (adjetivo sustantivado), éste (la tilde ortográfica indica que se trata de un pronombre y no de un determinante) $)^{8}$, que (que podría ser conjunción o pronombre relativo), etc. Seguidamente repartimos la Tabla 8, que incluye el texto de Queneau "Partes de la oración", entre los grupos dándole a cada uno de ellos dos tablas, para que comprueben si lo que han hecho es correcto o no. Tras dejar unos minutos, preguntamos por posibles errores en busca de las causas que los han creado y aclaramos las dudas. Después informamos a los discentes de que ese texto es un texto real que pertenece a un libro titulado Ejercicios de estilo. En dicho libro su autor, Raymond Queneau, trata de versionar una misma anécdota contándola de 27 formas diferentes.

Proponemos que cada grupo reconstruya esa anécdota tomando como referencia las palabras que aparecen en la fotocopia del texto "Partes de la oración" (Tabla 8). Se trata de generar el contenido entre todos los miembros del grupo, de manera que éstos han de aportar libremente sus ideas y tratar de buscar el consenso interno para quedarse con las opciones que les parezcan más adecuadas. Una vez pensada la anécdota, deberán plasmarla por escrito, teniendo en cuenta que su texto ha de incluir al menos quince de las palabras que aparecen en la fotocopia del texto de Queneau.

Cuando los textos están escritos, un portavoz de cada grupo lee el texto redactado en el grupo y los demás escuchan para valorar después el más parecido al original y el que más les ha gustado. Finalmente, tras escuchar las versiones de los alumnos, leemos en voz alta la versión de Queneau titulada "Relato" (Tabla 7). Entre todos se valoran las coincidencias que ha habido entre los textos escritos por los alumnos y el texto titulado "Relato" de Raymond Queneau, lo cual obliga a la comprensión del texto escuchado. Además se les cede la palabra para que opinen sobre cuál es la versión de los compañeros que más ha gustado?.

8 Al hilo de este ejemplo nos parece importante comentar en clase las modificaciones introducidas por la RAE en la última Ortografía de 2010. En el documento titulado Principales novedades de la última edición de la Ortografía de la lengua española (2010) del mismo organismo, se aclara que es posible prescindir de la acentuación en el adverbio sólo y los pronombres demostrativos.

${ }^{9}$ Inicialmente pensamos en una actividad más extensa en la que los alumnos, a partir de la versión "Partes de la oración", no debían escribir un texto, sino hablar sobre cuál podría ser la anécdota base. Tras llegar a acuerdos internos, un portavoz de cada grupo debería contar al resto de la clase la propuesta del grupo. Finalmente, después de escuchar a todos los portavoces de cada grupo, repartiríamos fotocopias del texto con la versión "Relato" de 
Texto 1:

Aquella bella mujer tenía el pelo largo y trenzado y portaba unos zapatos de plataforma y al ir subir al autobús alguien la puso una zancadilla adrede. Al darme cuenta de esto pretendí ayudarla pero un joven se me adelantó. Ellos se dirigieron al parque y éste la besó repetidamente en el cuello, rápidamente le propiné una paliza porque era mi hija. Más tarde mi hija y yo entablamos una gran discusión, y nuestro vecino al oirlo bajó a ver que sucedía.

Texto 2:

Se le había pasado la mañana y ya era mediodía. Lázaro veía en su reloj que el tiempo pasaba y el autobús que salía del Parque Monceau hacia el hospital no le esperaría. Tenía prisa debido a que su mujer estaba dando a luz y por culpa de su arrogancia, Lázaro se lo perdería. Al llegar a la estación se encontró la línea $\mathrm{S}$ cerrada debido a una revisión del motor, con su habitual soberbia, se soltó la cinta, pero se precipitó escaleras abajo y se desmayó.

Al despertar, vio una blanca figura alada la cual le dijo: - Soy San Pablo, bienvenido al cielo. Lázaro, sorprendido, dijo: - No puedo estar muerto, mi mujer está en el hospital pariendo, merezco una segunda oportunidad. -¿Eso crees?- dijo San Pablo - Eres tan arrogante que crees saberlo todo, pensabas que el niño no nacería hasta dentro de tres meses y te soltastes la cinta porque creías que no necesitaba revisión. Promete cambiar y te perdonaré. Así se lo prometió. Cuando despertó, Lázaro estaba en una cama del hospital junto a su mujer y a su hijo, al que decidió llamar Pablo.

Texto 3:

Una mañana como muchas otras, me puse mi abrigo, salí por la puerta trasera rodeando el parque. A lo lejos vi a una persona que me sonaba la cara el me saludo y me di cuenta que era mi antiguo compañero de clase, Lázaro, hacía tiempo que no nos hablabamos por una discursión que tuvimos, quedamos al mediodía para arreglarlo a tomar un café. Subí al autobús y me fui del trabajo.

Queneau, para que los discentes comprobaran a través de la lectura comprensiva el grado de aproximación a la versión original. Pero esta actividad no acabaría aquí, sino que habría una segunda parte. Manteniendo la misma agrupación, daríamos a cada grupo un par de noticias diferentes, de una extensión similar, pero no muy largas, y pediría a los alumnos que las leyeran y eligieran la que más les gustara. Cuando la hubieran elegido, deberían clasificar algunas de las palabras de la noticia que consideraran más importantes desde un punto de vista semántico, debiendo completar con al menos cinco palabras cada una de las categorías gramaticales trabajadas en la anterior actividad. Se trataría de que hicieran una versión de la noticia similar a la que Queneau hace en el texto "Partes de la oración". Una vez hecha dicha versión, todos los grupos intercambiarían sus versiones. A partir de la versión de los compañeros, cada grupo intentaría reconstruir la noticia original. Este momento, sería idóneo para recordar algunos aspectos relativos a la estructura y a la idiosincrasia de la noticia. Una vez escritas las correspondientes noticias, se compararían éstas con las noticias originales. Por último, el docente y los alumnos colgarían por las paredes del aula cada noticia real con su correspondiente versión, para que los alumnos pudieran leerlas en ratos libres y tuvieran ocasión de cotejarlas. 
Texto 4:

A mediodía, después del colegio, fui al Parque Monceau a coger el autobús y conocí a una joven con sombrero y abrigo de piel con botones que estaba de pie con un gran escote. Tenía el pelo largo y trenzado con una cinta.

A la mañana siguiente me la encontré otra vez. Empecé a hablar con ella pero no me daba conversación. Me caí en el autobús y ella me pisoteó. Entonces me di cuenta de que era sorda y ciega.

Tabla 10. Ejemplos de los textos escritos por los alumnos ${ }^{10}$.

- Evaluación metodológica:

La actividad se desarrolló tal y como estaba previsto inicialmente, no se detectó ninguna dificultad en la realización de la misma. Si bien, la redacción de los textos ocupó más tiempo del que en principio se previó, pero, tal y como se les manifestó a los alumnos, sorprendió la creatividad reflejada en los mismos, que superó incluso la de la anécdota del propio Queneau. Consideramos que lo idóneo sería que esta actividad se trabajara al hilo del texto narrativo, lo que permitiría a los alumnos reflexionar sobre las convenciones propias de esta tipología textual tales como la estructura o la importancia de la secuenciación cronológica. Además, en este marco, quedaría pendiente profundizar un poco más en los errores de redacción, no sólo los ortográficos y gramaticales, sino también los relacionados con la precisión léxica, la coherencia, cohesión y la estructura del texto.

Por último, aunque no dimos indicaciones precisas para realizar la actividad, pensamos que una vez más podría ayudar a los alumnos el hecho de concretar más la intervención y el papel de los alumnos dentro del grupo, así, por ejemplo, en el momento de generar el contenido de la anécdota que después deberán escribir, podríamos decirles que primero cada uno contara su idea inicial y después que entre todos eligieran por consenso las ideas que más les habían gustado de sus compañeros y trataran de organizar con ellas una anécdota de grupo.

\section{CONCLUSIONES}

Se ha presentado aquí una serie de actividades que permiten que en un primer momento el alumno focalice su atención en cuestiones formales relacionadas con la morfología, posteriormente se les pide a los alumnos que se trasciendan los contenidos formales para relacionarlos con el uso, todo ello sin renunciar a la concepción del objeto de estudio, la lengua, como instrumento de comunicación en el que la interacción cobra un papel destacado, algo que también viene reforzado por el planteamiento cooperativo de las actividades.

\footnotetext{
${ }^{10}$ Los textos que aparecen copiados aquí se corresponden con los textos de los alumnos, tal cual los escribieron ellos, de ahí las incorrecciones.
} 
Consideramos que en estas dos sesiones se atiende a las tres finalidades que, según Dolz et al. $(2009,125)$ ha de perseguir la enseñanza de una lengua, a saber: 1) comunicar, 2) reflexionar sobre la lengua y la comunicación y 3) construir referentes culturales. Esta última finalidad, tal y como explican estos autores, implica la vuelta a los textos literarios y a todo lo que atañe a los usos, la historia, la norma y el patrimonio de la lengua en general.

Estas dos sesiones se han elaborado con base en unas ideas teóricas diferentes a las tradicionales y demuestran que es posible otra forma de docencia, sin embargo, estos objetivos no son demasiado ambiciosos, somos conscientes de que esta propuesta no es sino una discreta aportación práctica, por ello, una vez que se ha demostrado que es posible plasmar la teoría en una secuenciación de actividades y que es posible llevar al aula dichas actividades, se abren nuevas líneas de investigación que no son las que se pretendía abordar aquí, pero que quedan pendientes para futuras investigaciones, entre ellas nos parece interesante investigar la eficacia de esta metodología en cuanto a los conocimientos linguísticos que los alumnos adquieren y si esta metodología mejora de algún modo la competencia comunicativa de los alumnos, esto es, el uso que hacen de la lengua. Consideramos que para extraer ideas fiables en este sentido, sería necesario hacer un estudio longitudinal, lo cual implica más de una sesión por grupo, algo que no fue viable en nuestro caso.

\section{BIBLIOGRAFÍA}

AGUILAR LÓPEZ, Ana María (2014): "La enseñanza de la morfología a través de la cooperación y colaboración: propuesta práctica", en Desarrollo Humano II, PENAA ACUÑA, B. (dir.), Madrid, Visión Libros, 151-174.

B.O.E. (2006): Real Decreto 1631/2006 de 29 de diciembre por el que se establecen las enseñanzas mínimas correspondientes a la Educación Secundaria Obligatoria [en línea], http://www.boe.es/diario_boe/txt.php?id=BOE-A-2007-238 [Consulta: 2 de febrero de 2015].

Consejo de Europa (2002): Marco Común Europeo de Referencia para las Lenguas [en línea], http://cvc.cervantes.es/ensenanza/biblioteca_ele/marco/ [Consulta: 2 de febrero de 2015].

DolZ, J., R. GAGNON y S. MosQuera (2009): "La didáctica de las lenguas: una disciplina en proceso de construcción" [en línea], en Didáctica. Lengua y Literatura, 21 , 117-141, http://revistas.ucm.es/index.php/DIDA/article/view/DIDA0909110117A/18815 [Consulta: 2 de febrero de 2015].

ERTMER P. A. y T. J. NeWBY (1993): "Conductismo, cognitivismo y constructivismo: una comparación de los aspectos críticos desde la perspectiva del diseño de instrucción" [en línea], en Performance Improvement Quarterly, 6, (4), 50-72, http://www.galileo.edu/pdh/wp-content/blogs.dir/4/files/2011/05/1.- 
ConductismoCognositivismo-y-Constructivismo.pdf [Consulta: 2 de febrero de 2015].

MANTECÓN RAMÍREZ, B. y F. ZARAGOZA CANALES, (1998): “La enseñanza de la gramática en la Enseñanza Secundaria Obligatoria" [en línea], en Revista Interuniversitaria de Formación del Profesorado, 31, 75-89, http://dialnet.unirioja.es/servlet/articulo?codigo=117968 [Consulta: 2 de febrero de 2015].

OXFORD, Rebecca L. (1997): "Cooperative learning, collaborative learning, and interaction: three communicative strands in the language classroom", en The Modern Language Journal, 81, (4), 443- 456.

PASTOR CeSTERos, Susana (2004): Aprendizaje de segundas lenguas. Lingüística aplicada a la enseñanza de idiomas, Alicante, Publicaciones Universidad de Alicante.

QUENEAU, Raymond (1987): Ejercicios de estilo. Versión de Antonio Fernández Ferrer, Madrid, Cátedra.

RAE (2010): Principales novedades de la última edición de la Ortografía de la lengua española [en línea], http://www.rae.es/sites/default/files/Principales_novedades_de_la_Ortografia_de _la_lengua_espanola.pdf [Consulta: 2 de febrero de 2015].

Río, María José del (1993): Psicopedagogía de la lengua oral: un enfoque comunicativo. Cuadernos de educación $n^{o} 12$, Barcelona, Ice - Horsori.

SANTOS GARGALLO, Isabel (1999): Lingüística aplicada a la enseñanza aprendizaje del español como lengua extranjera, Madrid, Arco Libros.

VV. AA. (2000): Competencia comunicativa. Documentos básicos en la enseñanza de lenguas extranjeras, Madrid, Edelsa. 